\title{
Criação e gestão ambiental de Áreas de Proteção Ambiental: entre atores, interesses, usos, conflitos e o dilema da conservação nos biomas brasileiros Mata Atlântica e Cerrado
}

\author{
Creation and management of Environmental Protection Areas: \\ among actors, interests, uses, conflicts and the dilemma of \\ conservation at Brazilian biomes Atlantic Forest and Cerrado
}

Maria do Socorro Ferreira da Silva http:/ / orcid.org/0000-0003-3656-5807 ms.ferreira.s@hotmail.com Universidade Federal de Sergipe, UFS, São Cristóvão, SE

Vicentina Socorro da Anunciação http:/ / orcid.org/0000-0001-8571-5109 vique56@hotmail.com Universidade Federal de Mato Grosso do Sul, UFMS, Campo Grande, MS

Hélio Mário de Araújo http:/ / orcid.org/0000-0002-6772-3217 heliomarioaraujo@yahoo.com.br Universidade Federal de Sergipe, UFSE, São Cristóvão, SE

\begin{abstract}
Resumo: Este artigo visa analisar a gestão ambiental e o dilema da conservação nas categorias do SNUC, especialmente a Área de Proteção Ambiental (APA), com ênfase na Mata Atlântica e no Cerrado. Boa parte da área destinada para Unidades de Conservação (UCs) no país foi decretada como APA, categoria bastante criticada pela literatura por envolver áreas intensamente urbanizadas, cujos usos para atividades turísticas, agropecuárias e mineradoras dificultam a gestão e conservação. É fundamental, nesse contexto, estabelecer parcerias com proprietários, reavaliar a proliferação das APAs, promover a conectividade florestal e priorizar a Educação Ambiental crítica na gestão participativa para dirimir os conflitos e estimular a conservação dos recursos naturais.
\end{abstract}

Palavras-chave: Biodiversidade, Conflitos socioambientais, Educação Ambiental, Gestão participativa. 


\begin{abstract}
This paper aims to analyze the environmental management and conservation dilemma in the SNUC categories, especially the Environmental Protection Area (APA), with emphasis on the Atlantic Forest and the Cerrado. Much of the area designated for Conservation Units (UCs) in the country has been decreed as APA, a category widely criticized by the literature for involving highly urbanized areas whose use for tourism, farming, and mining hinder the management and conservation. It is essential, in this context, to establish partnerships with owners, reevaluate the proliferation of APAs, promote forest connectivity and prioritize critical Environmental Education in participatory management to resolve conflicts and stimulate conservation of natural resources.
\end{abstract}

Keywords: Biodiversity, Socio-environmental conflicts, Environmental education, Participative management.

Resumen: Este artículo pretende analizar la gestión ambiental y conservación en las categorías del SNUC, especialmente el Área de Protección Ambiental (APA), con énfasis en la Mata Atlántica y en el Cerrado. Gran parte de la zona destinada a unidades de conservación (UCs) en el país fue decretada como APA, una categoría ampliamente criticada por la literatura por involucrar áreas intensamente urbanizadas cuyos usos para actividades turísticas, agropecuarias y mineras dificultan la gestión y conservación. Es esencial, con este contexto, establecer alianzas con los propietarios, reevaluar la proliferación de APAs, promover la conectividad forestal y priorizar la Educación Ambiental crítica en la gestión participativa para dirimir los conflictos y estimular la conservación de los recursos biofísicos.

Palabras-clave: Biodiversidad, Conflictos socioambientales, Educación ambiental, Gestión participativa.

\title{
INTRODUÇÃO
}

No contexto mundial, o Brasil é o país que detém maior biodiversidade, destacando-se por agrupar entre $15 \%$ e $20 \%$ da biodiversidade mundial e o maior número de espécies endêmicas do planeta (Drummond \& Antonini, 2006). Essa biodiversidade, ainda que em boa parte em florestas fragmentadas, está representada nos biomas ${ }^{1}$ Amazônia, Mata Atlântica, Cerrado, Caatinga, Pantanal e Pampas, cuja diversidade biológica encontra-se ameaçada devido ao desmatamento intensivo para atender às demandas socioeconômicas. O conceito de bioma está associado a uma unidade de paisagem que apresenta fisionomia e fatores ecológicos similares, representada por um conjunto de ecossistemas (Romariz, 2008).

As causas do desmatamento no Brasil têm origem na implantação de infraestrutura (estradas, hidrelétricas, barragens), na expansão urbana, no processo de industrialização, no desenvolvimento da agropecuária, na extração florestal e mineral, entre outras atividades. Nesse sentido, a supressão da vegetação para atender às demandas socioeconômicas tem implicado na fragmentação florestal e consequente perda da biodiversidade.

1 Utiliza-se o termo bioma devido às informações sobre as UCs estarem agrupadas e disponibilizadas Cadastro Nacional de Unidades de Conservação (CNUC) por bioma. As informações divulgadas estão vinculadas ao Ministério de Meio Ambiente com a colaboração dos órgãos gestores das três esferas governamentais: federal, estadual e municipal. 
A supressão de florestas esteve diretamente associada às políticas desenvolvimentistas adotadas no país, que priorizavam modelos econômicos voltados à produção insustentável, a exemplo dos ciclos econômicos da cana-de-açúcar e do café (Silva, 2012). Além de reduzir boa parte da Mata Atlântica, o avanço da fronteira agrícola tem dizimado extensas áreas e continua ameaçando o Cerrado e a Amazônia. Ao longo deste texto serão apresentadas informações sobre as Unidades de Conservação (UCs) desses biomas, porém a análise será mais aprofundada para a Mata Atlântica e o Cerrado. Esses dois biomas, caracterizados pela sua biodiversidade, ainda que seus hábitats estejam altamente fragmentados, estão entre os 35 hotspots mundiais que, devido ao alto número de endemismo e às espécies ameaçadas de extinção, demandam urgência de ações destinadas à conservação (Myers, 1997; Myers, Mittermeier, Mittermeier, \& Kent, 2000; Mittermeier et al., 2004).

Mittermeier et al. (2004) ressaltam a importância da conservação de áreas de florestas tropicais com alta biodiversidade que ainda se encontram em condições relativamente intactas, denominadas Grandes Regiões Naturais. Embora essas áreas estejam menos ameaçadas, quando comparadas com os hotspots, também estão sob crescentes e fortes ameaças pela ação antrópica. No Brasil, estão inclusos na lista dessas Grandes Regiões Naturais a Amazônia, o Pantanal e a Caatinga (Mittermeier et al., 2004), os quais, juntamente com os hotspots, são considerados prioritários para conservação. Assim, estratégias eficazes de gestão de UCs são necessárias para evitar a perda da biodiversidade e recursos desses espaços.

O Cerrado, segundo maior bioma da América Latina e do Brasil, com mais de dois milhões de quilômetros quadrados (Ab'Saber, 2003), era considerado a savana mais rica no contexto mundial (Silva, 2005; Klink \& Machado, 2005). Com uma diversidade de ecossistemas, representando $5 \%$ da biodiversidade planetária e um terço da biodiversidade do país (Silva, 2005), apresentava 44\% de sua flora endêmica (Empresa Brasileira de Pesquisa Agropecuária [EMBRAPA], 2005). As savanas da região central do Brasil tiveram praticamente metade de sua cobertura vegetal removida $(48,4 \%)$, passando de $2.038 .953 \mathrm{~km}^{2}$ para 1.052.708 $\mathrm{km}^{2}$ até 2008 (Instituto Brasileiro de Geografia e Estatística [IBGE], 2010). Nos anos de 2009 e 2010, a taxa anual de desmatamento chegou a 0,3\%, considerada a maior taxa de supressão quando comparada com os demais biomas brasileiros (Ministério de Meio Ambiente [MMA]/IBAMA, 2011). Embora tenha ocorrido uma redução nessa taxa entre os anos de 2014 e 2015, os índices ainda são considerados elevados para o Cerrado. Em 2016 foram desmatados $6.777 \mathrm{~km}^{2}$, e em 2017 esse número aumentou para $7.408 \mathrm{~km}^{2}$. Nesse ritmo, a biodiversidade desse bioma encontra-se extremamente ameaçada em virtude da expansão do agronegócio (Greenpeace, 2018). Em 2019, o Ministério da Ciência, Tecnologia, Inovações e Comunicações (MCTIC) e o Ministério do Meio Ambiente divulgaram os dados sobre desmatamento no bioma, correspondente ao período de agosto de 2018 a julho de 2019, que totalizou que totalizou $6.484 \mathrm{~km}^{2}$ (Instituto Nacional de Pesquisas Espaciais [INPE], 2019a). Nessas análises a vegetação nativa suprimida no Cerrado foi $2 \%$ menor quando comparada com o ano anterior, porém com valor absoluto muito próximo (INPE, 2019a). No tocante aos Estados, no ano de 2019, Tocantins foi o que apresentou a maior 
área de vegetação nativa suprimida $\left(1.495,69 \mathrm{~km}^{2}\right)$, seguido pelo Maranhão $(1.309,50$ km²) e Bahia $\left(832,42 \mathrm{~km}^{2}\right)$ (INPE, 2019a).

A Mata Atlântica chegou a apresentar apenas 7\% de sua cobertura original (Ab'Saber, 2003), o que a colocou entre os cinco primeiros biomas no ranking dos hotspots. É considerada o único bioma composto por ecossistemas de florestas tropicais da América do Sul que inclui vegetação de mangue e de restinga (Conservação Internacional, 2018), compondo um mosaico de unidades fitogeográficas e tipologias vegetacionais (MMA/SBF, 2002). No período compreendido entre 2005 a 2008, a Mata Atlântica teve uma área desmatada equivalente a 102.938 ha, o que reforça sua inserção entre os biomas mais ameaçados no contexto mundial. Entre 2015 e 2016, foram desmatados 29.075 ha nos 17 Estados do bioma Mata Atlântica, o que representou um aumento de 57,7\% em relação ao biênio anterior (2014-2015), quando se desmatou 18.433 ha. Embora tenha sido registrada uma redução de 56,8\% na taxa de desmatamento de 2016 a 2017 (SOS Mata Atlântica/INPE, 2018). Contudo, o mesmo relatório menciona que houve uma pequena recuperação na área de cobertura vegetal do bioma nos últimos anos, chegando a atingir $12,4 \%$ da floresta original. Entre 2017 e 2018 o desmatamento caiu 9,3\% em relação ao período anterior (2016-2017), que por sua vez já tinha sido o menor registrado pela série histórica do Atlas da Mata Atlântica (INPE, 2019b). Entretanto, é fundamental analisar as informações por estados, pois cinco ainda mantêm altos índices de desmatamento quando comparada com o período anterior: Minas Gerais (3.379 ha), Paraná (2.049 ha), Piauí (2.100 ha), Bahia (1.985 ha) e Santa Catarina (905 ha) (INPE, 2019b).

No ano de 2000 foi criado através da Lei Federal nº 9.985 o Sistema Nacional de Unidades de Conservação $\left(S N U C^{2}\right)$, que instituiu a criação, implementação e gestão das UCs, dividindo-as em dois grupos: Proteção Integral, que permite o uso indireto dos recursos naturais; e Uso Sustentável, que visa compatibilizar a conservação da natureza com o uso sustentável de uma parcela dos recursos naturais. Todavia, os órgãos gestores têm encontrado dificuldades para garantir a conservação ambiental, pois as potencialidades paisagísticas e os recursos naturais inseridos nesses Espaços Territoriais Especialmente Protegidos $\left(\mathrm{ETEP}^{3}\right)$ despertam interesses de diversos atores sociais pela apropriação, controle e uso do território. Tal situação tem engendrado conflitos em virtude dos usos estabelecidos que dificultam e/ou impedem a gestão e implementação das unidades. Nesse sentido, com base numa reflexão teórico-metodológica, este artigo apresenta uma análise sobre a gestão ambiental, considerando-se os atores sociais, os interesses, os usos, os conflitos e o dilema da conservação das categorias do SNUC, especialmente a Área de Proteção Ambiental (APA), com maior ênfase na Mata Atlântica e Cerrado.

As APAs são definidas no Art. 15 do SNUC como:

Uma área em geral extensa, com um certo grau de ocupação humana, dotada de atributos abióticos, bióticos, estéticos ou culturais especialmente importantes para a

2 Disponível em http://www.planalto.gov.br/ccivil_03/leis/L9985.htm

3 Fazem parte dos ETEP as Áreas Protegidas (Unidades de Conservação, Territórios Quilombolas e as Terras Indígenas), as áreas de Reserva Legal e as Áreas de Preservação Permanente (Leuzinger, 2007). 
qualidade de vida e o bem-estar das populações humanas, e tem como objetivos básicos proteger a diversidade biológica, disciplinar o processo de ocupação e assegurar a sustentabilidade do uso dos recursos naturais.

Apontam Silva e Souza (2013) que as APAs são criadas para conservar a biodiversidade e melhorar a qualidade de vida das comunidades envolvidas, incluindo os povos tradicionais (quilombolas, ribeirinhos, indígenas, caiçaras, pastorais, populações extrativistas, como pescadores, caçadores e coletores), além de pequenos agricultores e assentados bem como populações urbanas. Entretanto, na prática, por ser a categoria que permite vários tipos de usos, são evidentes suas contradições ao atender também aos atores sociais que dispõem de poder político e econômico, explorando, expropriando e/ou espoliando as comunidades que têm sua base de sustento afetada (Silva \& Souza, 2013) e/ ou reduzindo a qualidade e quantidade de bens ambientais, como água e biodiversidade.

No contexto nacional, os territórios de várias APAs, detentoras de belezas cênicas, vêm sendo utilizados para atividades turísticas. Dentre os exemplos, pode-se citar as APAs localizadas no estado da Bahia: Coroa Vermelha, na faixa costeira dos municípios de Porto Seguro e Santa Cruz Cabrália; e Caraíva/Trancoso, no litoral de Porto Seguro, ambas criadas em 1993; e a APA de Santo Antônio, em Santa Cruz Cabrália (Santa Cruz Cabrália, 2016), cujas UCs possuem significativa relevância para o turismo. No estado de São Paulo pode-se mencionar; as APAs de Corumbataí, Botucatu e Tejupá, em Analândia (São Paulo) e da Escarpa Devoniana (que abrange 12 municípios do Paraná), aflorantes do Aquífero Guarani, criadas em 1983 e 1992, respectivamente, para proteger as cuestas basálticas e areníticas, fragmentos de Mata Atlântica e Cerrado, num cenário de belas paisagens (cachoeiras, morros esculpidos, cuestas, cavernas) cujos atrativos turísticos movimentam a economia de suas regiões (Perinoto, 2007; Alves et al., 2019), mas que também evidenciavam impactos socioambientais como resultado da atividade turística (Assoni, 2007; Carmo, 2009).

Ao longo da costa litorânea, na Mata Atlântica, é notória a existência de várias UCs cujos territórios foram utilizados para construção de resorts e/ ou hotéis luxuosos destinados para aqueles atores sociais que dispõem de recursos financeiros para usufruir das belas paisagens naturais (Silva, 2012). A autora reforça que, se por um lado, os empreendedores, sejam eles nacionais ou internacionais, se apropriam do território e o usam como forma de geração de riqueza; por outro lado, as comunidades locais e tradicionais são espoliadas e/ou excluídas desses territórios. Nessa abordagem, Saquet (2007, p. 127) destaca que o território é produto e condição de territorialização, produzido espaço-temporalmente por um grupo dominante pelo exercício de poder determinado pelas territorialidades cotidianas. Logo, o território é essencialmente um espaço definido e delimitado por e a partir das relações de poder (Souza, M. J. L., 2003, p. 78).

Assim, em virtude dos interesses que estão em jogo, discute-se a implantação priorizada da categoria APA nas três esferas governamentais, em detrimento de categorias de uso mais restrito, o que tem colocado em risco a conservação dos remanescentes florestais ainda existentes. Ademais, as contradições entre o uso e o dilema da conservação 
fazem parte da história da biodiversidade nos biomas nacionais, com categorias criadas e implementadas para atender aos anseios de parcela da população, como é o caso das Florestas Nacionais (FLONAS), e especialmente dos Parques Nacionais (PARNAS), sob a égide do mito da natureza intocada (Diegues, 2008), mas que na prática exclui e/ou expulsa comunidades locais.

Para compreender a complexidade que envolve a gestão ambiental de Unidades de Conservação nos biomas nacionais, a pesquisa foi realizada com base em reflexões teórico-metodológicas ancoradas em levantamento bibliográfico e documental sobre Unidades de Conservação, gestão ambiental, biomas nacionais, especialmente Mata Atlântica e Cerrado, conflitos socioambientais, biodiversidade, impactos socioambientais, Educação Ambiental (EA) crítica, legislação ambiental, entre outros temas.

A pesquisa tem caráter quali-quantitativo pois, além da discussão inerente às potencialidades e fragilidades que dificultam a gestão ambiental das UCs, foram analisadas informações disponibilizadas pelo Ministério do Meio Ambiente (MMA), a partir do Cadastro Nacional de Unidades de Conservação (CNUC), cujas tabelas apresentam a extensão territorial decretada para os dois grupos de UCs do SNUC. Foram consideradas as doze categorias protegidas por esse instrumento jurídico, as três esferas governamentais gestoras e as informações por biomas terrestres.

Com relação às análises das informações obtidas no Cadastro Nacional de Unidades de Conservação (CNUC), é importante esclarecer que os dados podem variar, pois nem todos os entes federativos, especialmente os municípios, cadastram suas UCs. Assim, o artigo apresenta um panorama parcial, mas bastante aproximado, do cenário nacional.

\section{AS CATEGORIAS DO SNUC E AS IMPLICAÇÕES NA GESTÃO AMBIENTAL DAS UNIDADES DE CONSERVAÇÃO}

O Brasil completou vinte anos da aprovação do SNUC, responsável pela unificação de categorias que estavam dispersas em vários instrumentos jurídicos, além de criar novas (Quadro 1). Embora o SNUC seja considerado um avanço na legislação brasileira, parte das UCs continua desprovida de mecanismos que garantam sua conservação, como o plano de manejo. Além disso, o entendimento na diferenciação entre as categorias no mesmo grupo, por exemplo, ainda não atingiu um consenso que facilite a decisão dos gestores no processo de indicação da categoria ideal para a UC pretendida.

No tocante às similaridades entre as categorias, os questionamentos apontados são compartilhados com Dourojeanni e Pádua (2013):

- Quais as diferenças efetivas entre Reserva Biológica (REBIO) e Estação Ecológica (EE)?

Com relação às divergências, há categorias em que é possível encontrar diferença apenas no quesito regime de propriedade do território, como por exemplo "posse e domínio público", que prevê desapropriação (como é o caso da UC de uso sustentável Reserva de Fauna), enquanto "terras públicas e privadas" (como é o caso da UC de proteção integral Refúgio de Vida Silvestre) prevê a possibilidade de desapropriação. 
Quadro 1: Principais características e regime de propriedade das UCs definidas no SNUC.

\begin{tabular}{|c|c|c|}
\hline Categorias & Principais características & $\begin{array}{l}\text { Regime de propriedade do } \\
\text { território }\end{array}$ \\
\hline \multicolumn{3}{|c|}{ UNIDADES DE CONSERVAÇÃO DE PROTEÇÃO INTEGRAL } \\
\hline Estação Ecológica - EE & $\begin{array}{l}\text { Preservação da natureza; realização de pesquisas } \\
\text { científicas autorizadas pelo órgão gestor; prevê } \\
\text { visita pública somente com finalidade educativa. }\end{array}$ & $\begin{array}{l}\text { Posse e domínio público (prevê } \\
\text { desapropriação) }\end{array}$ \\
\hline $\begin{array}{l}\text { Reserva Biológica - } \\
\text { REBIO }\end{array}$ & $\begin{array}{l}\text { Preservação integral da biota e dos demais } \\
\text { atributos; realização de pesquisas científicas } \\
\text { autorizadas pelo órgão gestor; proibida visita } \\
\text { pública exceto com objetivo educacional } \\
\text { autorizada pelo órgão gestor. }\end{array}$ & $\begin{array}{l}\text { Posse e domínio público (prevê } \\
\text { desapropriação) }\end{array}$ \\
\hline $\begin{array}{l}\text { Parque Nacional - } \\
\text { PARNA }\end{array}$ & $\begin{array}{l}\text { Preservação de ecossistemas naturais com grande } \\
\text { relevância ecológica e beleza cênica; realização } \\
\text { de pesquisas científicas; desenvolvimento de } \\
\text { atividades educacionais, de recreação e de } \\
\text { turismo ecológico. }\end{array}$ & $\begin{array}{l}\text { Posse e domínio público (prevê } \\
\text { desapropriação) }\end{array}$ \\
\hline $\begin{array}{l}\text { Monumento Natural - } \\
\text { MONA }\end{array}$ & $\begin{array}{l}\text { Preservação de sítios naturais raros e de beleza } \\
\text { cênica; prevê visita pública. }\end{array}$ & $\begin{array}{l}\text { Áreas públicas ou privadas } \\
\text { (possibilidade de desapropriação) }\end{array}$ \\
\hline $\begin{array}{l}\text { Refúgio de Vida Silvestre } \\
\text { - RVS }\end{array}$ & $\begin{array}{l}\text { Proteger ambientes naturais, assegurando } \\
\text { condições para a existência ou reprodução de } \\
\text { espécies; realização de pesquisa científica; prevê } \\
\text { visita pública. }\end{array}$ & $\begin{array}{l}\text { Áreas públicas ou privadas } \\
\text { (possibilidade de desapropriação) }\end{array}$ \\
\hline \multicolumn{3}{|c|}{ UNIDADES DE CONSERVAÇÃO DE USO SUSTENTÁVEL } \\
\hline $\begin{array}{l}\text { Área de Proteção } \\
\text { Ambiental - APA }\end{array}$ & $\begin{array}{l}\text { Proteger a diversidade biológica; disciplinar } \\
\text { o processo de ocupação e assegurar a } \\
\text { sustentabilidade dos recursos naturais; realização } \\
\text { de pesquisa científica; prevê visita pública. }\end{array}$ & $\begin{array}{l}\text { Terras públicas ou privadas (não } \\
\text { prevê desapropriação) }\end{array}$ \\
\hline $\begin{array}{l}\text { Área de Relevante } \\
\text { Interesse Ecológico - } \\
\text { ARIE }\end{array}$ & $\begin{array}{l}\text { Abriga exemplares raros da biota regional; } \\
\text { regular o uso dos recursos existentes. }\end{array}$ & $\begin{array}{l}\text { Terras públicas ou privadas } \\
\text { (possibilidade de desapropriação) }\end{array}$ \\
\hline $\begin{array}{l}\text { Floresta Nacional - } \\
\text { FLONA }\end{array}$ & $\begin{array}{l}\text { Uso múltiplo e sustentável dos recursos } \\
\text { florestais; permite a permanência de populações } \\
\text { tradicionais; realização de pesquisa científica; } \\
\text { prevê visita pública. }\end{array}$ & $\begin{array}{l}\text { Posse de domínio público (prevê } \\
\text { desapropriação) }\end{array}$ \\
\hline $\begin{array}{l}\text { Reserva Extrativista - } \\
\text { RESEX }\end{array}$ & $\begin{array}{l}\text { Conciliação da sustentabilidade com atividades } \\
\text { extrativistas tradicionais para subsistência; } \\
\text { realização e incentivo de pesquisa científica; } \\
\text { prevê visita pública. }\end{array}$ & $\begin{array}{l}\text { Posse de domínio público (prevê } \\
\text { desapropriação) }\end{array}$ \\
\hline Reserva de Fauna & $\begin{array}{l}\text { Manejo econômico e sustentável dos recursos } \\
\text { faunísticos; realização de pesquisa científica; } \\
\text { prevê visita pública. }\end{array}$ & $\begin{array}{l}\text { Posse de domínio público (prevê } \\
\text { desapropriação) }\end{array}$ \\
\hline $\begin{array}{l}\text { Reserva de } \\
\text { Desenvolvimento } \\
\text { Sustentável - RDS }\end{array}$ & $\begin{array}{l}\text { Preservar a natureza e assegurar as condições } \\
\text { para a reprodução das populações tradicionais; } \\
\text { abriga populações tradicionais; permite e } \\
\text { incentiva realização de pesquisa científica; } \\
\text { permite e incentiva a visita pública. }\end{array}$ & $\begin{array}{l}\text { Posse de domínio público (prevê } \\
\text { desapropriação) }\end{array}$ \\
\hline $\begin{array}{l}\text { Reserva Particular de } \\
\text { Patrimônio Natural - } \\
\text { RPPN }\end{array}$ & $\begin{array}{l}\text { Conservar a diversidade biológica; permite a } \\
\text { realização de pesquisa; prevê visita com objetivos } \\
\text { turísticos, recreativos e educacionais. }\end{array}$ & $\begin{array}{l}\text { Área privada gravada com } \\
\text { perpetuidade }\end{array}$ \\
\hline
\end{tabular}

Fonte: Adaptado de Silva (2012). 
As semelhanças nas características entre categorias dificultam o processo e acabam trazendo concepções e decisões equivocadas no processo de criação das UCs. Pode-se citar o exemplo da APA, por ser uma categoria cujo entendimento tem levado a crer que permite todo tipo de uso e não precisar de processo de desapropriação, sendo, teoricamente, mais fácil de gerir. Entretanto, essa categoria também gera custos para os órgãos gestores.

Com relação à categoria Floresta Nacional, trata-se, comumente, de espaços utilizados para exploração de madeira e recursos como extração mineral (Dourojeanni \& Pádua, 2013). Silva (2012) chama atenção no tocante à exploração florestal nas FLONAS e às suas contradições, pois foram criados instrumentos jurídicos, como a Lei n. 11.284/20064, para legalizar o uso dos recursos naturais nos "territórios da conservação" por grandes empreendedores. A referida Lei dispõe sobre a gestão de florestas públicas para produção sustentável, institui o Serviço Florestal Brasileiro (SFB), na estrutura do Ministério do Meio Ambiente (atualmente, e muito significativamente, alocado no Ministério da Agricultura, Pecuária e Abastecimento), e cria o Fundo Nacional de Desenvolvimento Florestal - FNDF. Nessa Lei, as florestas são denominadas de públicas, sendo geridas pelas esferas federal, estadual e municipal, visando a produção florestal para o abastecimento renovado do conjunto das substâncias necessárias à conservação da vida, bem como à nutrição, à alimentação e ao sustento. A Lei permite conceder a particulares o direito de explorar de forma 'sustentável' os produtos oferecidos pelas florestas. Com base nos critérios técnicos, a concessão ocorrerá a partir de processo licitatório a pessoas jurídicas, que podem usar os recursos por até 40 anos.

Nas análises de Silva (2012), a exploração ocorre já há muito tempo, reforçando a hipótese de que a Lei veio regularizar os usos, privilegiando os atores sociais que dispõem de poder político e econômico, o que sem dúvida traz à tona a necessidade de rever as características de categorias como a FLONA, por exemplo.-

Os usos evidenciam a fragilidade na aplicabilidade da legislação ambiental, e, como consequência, ocorre a dilapidação das florestas juntamente com sua biosociodiversida$\mathrm{de}^{5}$, pois, para além dos recursos naturais, está envolvida também a dimensão humana representada pelas comunidades tradicionais com seus modos de vida e seus saberes ambientais, que também serão perdidos. Nesse sentido, é pertinente questionar: As UCs são criadas para quê e para quem? O que restará das Florestas Públicas após 40 anos de exploração? Quais os impactos socioambientais ocasionados nessas áreas e sentidos pelas populações? Evidentemente são questões problemáticas, mas que merecem uma profunda reflexão, sobretudo por parte dos que têm poder de decisão.

4 Lei $n^{0} 11.428$, de 22 de dezembro de 2006. Dispõe sobre a utilização e proteção da vegetação nativa do Bioma Mata Atlântica, e dá outras providências. Disponível em http://www.planalto.gov.br/ccivil_03/_ato2004-2006/2006/lei/111428.htm.

5 Considera a diversidade cultural humana (diversidade de línguas, crenças, religiões, práticas de manejo do solo, expressões artísticas, tipos de alimentação e diversos atributos humanos) (Albagli, 1998). 


\section{O DILEMA DA GESTÃO AMBIENTAL EM UNIDADES DE CONSERVAÇÃO}

A gestão ambiental da UC é permeada por entraves e desafios, pois como já foi dito, envolve simultaneamente atores sociais e interesses diversos de usos e relações conflitivas configurados nos territórios. Diante dessas divergências, esses espaços são palco de conflitos socioambientais que dificultam e/ou impedem a gestão ambiental, definida por Quintas como:

um processo de mediação de interesses e conflitos entre atores sociais que agem sobre os meios físico-natural e construído. Este processo de mediação define e redefine, continuamente, o modo como os diferentes atores sociais, através de suas práticas, alteram a qualidade do meio ambiente e também como se distribuem os custos e os benefícios decorrentes da ação desses agentes (2006, pp. 18-19).

Acselrad (2004) considera conflitos socioambientais como aqueles que envolvem atores sociais com interesses diversos pela apropriação, pelo uso e pela significação do território, cujo conflito ocorre quando pelo menos um dos grupos tem a continuidade das formas sociais de apropriação do território prejudicada ou ameaçada devido aos impactos indesejáveis, como resultado das práticas estabelecidas, refletindo negativamente no solo, na água, no ar, na fauna e na flora.

Os territórios das UCs são marcados por múltiplas territorialidades e por conflitos socioambientais, pois os interesses e as decisões de grupos dominantes não têm considerado os interesses dos demais atores sociais. Nessas análises, reforçam-se as concepções de Souza (Souza, M.J.L., 2003) quando considera que o território é definido primeiramente pelo "poder", tendo, assim, a dimensão política, antes de qualquer outra, como definidora de seu perfil. Porém, isso não quer dizer que a dimensão cultural (o simbolismo, as teias de significado, as identidades) e a econômica (o trabalho, os processos de produção e circulação de bens) não sejam importantes e/ou não estejam contempladas ao lidar com esse conceito.

Nos territórios das UCs, portanto, os conflitos socioambientais se intensificam em virtude da assimetria dos poderes políticos e econômicos no tocante ao processo decisório. Para Layrargues (2000), as decisões podem definir a distribuição dos ganhos e das perdas, mas comumente os benefícios para alguns atores sociais podem ser prejudiciais e/ou mesmo fatais para outros. Para ilustrar podem ser citadas as comunidades tradicionais que convivem com os efeitos das injustiças ambientais, sendo comumente expulsas ou espoliadas dos seus territórios, ou seja, impedidas de desenvolver suas práticas extrativistas, de manter seus modos de vida. Isso corrobora as injustiças ambientais em face da distribuição ecológica desigual, como abordam Acselrad, Mello e Bezerra (2009). Alves e Santos (2017), por sua vez, reforçam como a distribuição desigual dos bônus gerados pelas atividades econômicas para os atores sociais com maior poder de barganha (empresariais, estatais, entre outros), e dos ônus, especialmente para as comunidades que vivem dentro 
ou no entorno dos empreendimentos (grupos vulneráveis, as comunidades tradicionais), configura as injustiças ambientais e a consequente luta por justiça ambiental ${ }^{6}$.

Quanto aos prejuízos socioambientais, como resultado das decisões e dos usos insustentáveis que interferem na conservação das UCs e/ou de outras Áreas Protegidas (APs), na Mata Atlântica e no Cerrado, pode-se mencionar a perda da biodiversidade e a questão hídrica. Em virtude do alto grau de desmatamento, inclusive em Áreas de Preservação Permanente (APPs), como as margens dos rios, o Brasil enfrenta sérios problemas para o abastecimento de água, especialmente em grandes centros urbanos onde as populações convivem com racionamentos constantes ou mesmo falta de água.

Pelo exposto, visto as relações de poder estabelecidas nesses territórios desiguais e contraditórias, que expropriam e/ou espoliam grupos sociais excluídos do poder decisório, considerando-se a legislação vigente, os usos estabelecidos nessas áreas contradizem os princípios pelos quais as UCs foram criadas. Assim, os conflitos eclodem diante dos tensores antrópicos que comprometem a conservação das UCs, seja na Mata Atlântica, no Cerrado, ou em qualquer outro bioma. Embora se trate de biomas distintos, a territorialização das atividades tem implicado o afloramento de conflitos socioambientais engendrados em função dos múltiplos usos que dificultam a gestão desses ambientes.

A Mata Atlântica encontra-se representada por fragmentos florestais comumente localizados entre áreas intensamente urbanizadas e/ou envolvidas por matrizes de pastagens e cultivos de monoculturas. Assim, reestabelecer a conectividade e proteger a biodiversidade desses remanescentes é sem dúvida um dos desafios enfrentados pela gestão ambiental. Nessa análise, os dados mais recentes reforçam as estimativas de Guimarães (2005) e Mesquita, Cole e Leite (2006), quando há alguns anos já anunciavam que mais de $80 \%$ dos remanescentes florestais do bioma Mata Atlântica estariam localizados em propriedades particulares, o que torna ainda mais complexa a situação. Para Guimarães (2005), é fundamental estabelecer parcerias com pequenos proprietários com vistas à conservação dos fragmentos em suas propriedades em troca de pagamentos pelos serviços ambientais $^{7}$ prestados. Além das APPs e as Reservas Legais (RLs) estarem previstas como obrigatórias na Lei Florestal (Lei n. 12.651), em alguns Estados do Brasil, como por exemplo, Mato Grosso do Sul, existem também iniciativas a partir do Programa Manancial Vivo (PMV), na APA do Córrego Guariroba, no município de Campo Grande, destinado a apoiar e estimular a conservação dos recursos hídricos são utilizados para o abastecimento local.

O bioma Cerrado tem singular importância hídrica, uma vez que em seu território estão as nascentes das três maiores bacias hidrográficas da América do Sul: Amazônica/ Tocantins, São Francisco e Prata (Silva, 2005; Salles, 2008; MMA/IBAMA, 2011), responsáveis pelo abastecimento dos reservatórios subterrâneos, pois além da abundância de

6 Mochiutti e Guimarães (2018) relatam a luta da comunidades dos Campos Gerais, no Paraná, contra projeto de lei que previa a drástica redução da APA da Escarpa Devoniana, no Bioma Mata Atlântica, que visava privilegiar setores da mineração e do agronegócio na expoliação do pouco que ainda está preservado pelo zoneamento do plano de manejo. Foi uma mobilização tipicamente urbana que envolveu diversos segmentos da sociedade local, com apoio massivo da mídia, e que resultou no arquivamento da proposta.

7 É um instrumento econômico de estímulo aos proprietários à conservação dos remanescentes florestais das Áreas de Preservação Permanente (APP) e da Reserva Legal (RL) (Ganem, 2015). 
recursos hídricos superficiais, o Cerrado também é conhecido pelo seu elevado potencial de águas subterrâneas diante da presença do Aquífero Guarani (Botelho, 2010).

Silva (2005) reforça que a localização do Cerrado, associada às características de suas extensas chapadas planas, de solos profundos, geologicamente antigos e permeáveis, faz da região a verdadeira caixa d'água do país que alimenta várias bacias hidrográficas, inclusive aquelas localizadas em outros biomas. O autor chama atenção para a importância da vegetação na manutenção dessa reserva hídrica, mas, no entanto, até 2010 o bioma já havia perdido 48,5\% de sua cobertura original (MMA/IBAMA, 2011).

Ainda com relação ao Cerrado, para Salles (2008, p. 259), "a ocupação desordenada a partir dos anos de 1980 e a implantação de um modelo de desenvolvimento voltado para agricultura de exportação", especialmente na região Centro-Oeste, foram fatores determinantes para que o Cerrado se tornasse um dos biomas mais ameaçados do mundo. Esse avanço tem ultrapassado as fronteiras para outras regiões detentoras do bioma, como a região Nordeste (Maranhão, Piauí e Bahia, especialmente).

Silva (2005) destacou que a partir da inauguração da cidade de Brasília esse bioma começou a ser mais intensamente ocupado, embora já vivessem na região cerca de 11 milhões de pessoas em 1960. Foi entre 1972 e 1994 que o Estado brasileiro, em parceria com agências internacionais, investiu U\$1,7 bilhão em projetos de desenvolvimento no Cerrado, atingindo os estados de Minas Gerais, Mato Grosso, Mato Grosso do Sul, Goiás, Bahia, Tocantins e Maranhão, cujas monoculturas foram em sua maioria implementadas por agricultores da região Sul (Ribeiro, 1997b apud Silva, 2005, p. 233). Como resultado do lado perverso e arcaico da implantação do agronegócio, o estado de Mato Grosso foi recordista no desmatamento em 2003, bem como apresentou o maior índice de conflitos no campo (Silva, 2005).

Nesse bioma, o desmatamento para atender às demandas da expansão agropecuária e do agronegócio global ocorre numa velocidade que compromete efetivamente suas potencialidades hídrica e fitogeográfica. Silva (2005) enfatiza que a biodiversidade e a função hidrológica das chapadas estão cada vez mais ameaçadas em virtude do modelo de ocupação moderno, predatório e excludente, priorizando as monoculturas, produtoras de commodities, num processo acelerado. Para o autor, além da perda da biosociodiversidade, trata-se de um processo de erosão cultural, de modos de vida e de apropriação da natureza em prol da produção e geração de riquezas e da exclusão de comunidades indígenas e camponesas (negras e mestiças) que habitavam e habitam o Cerrado brasileiro.

Essa nova dinâmica, aliada tanto à conjuntura externa favorável à exportação de soja quanto ao apoio governamental durante o Governo Lula, contribuiu para o avanço da fronteira do agronegócio para regiões como o oeste da Bahia, o sul do Maranhão e do Piauí e diversas localidades do Tocantins, o sul e nordeste de Mato Grosso do Sul, o centro e sudeste de Mato Grosso, o Triângulo Mineiro sul e o leste de Goiás (Silva, 2005). Ademais, o autor reforça que, além da produção de grãos, o Cerrado era o principal suporte das áreas de pastagens e das monoculturas de eucalipto que se expandiram para o Maranhão e o Piauí, onde siderúrgicas instaladas transformavam o Cerrado em carvão, ameaçando a biodiversidade do bioma. 
Salles (2008) reforça as análises, ressaltando que o uso acelerado dos recursos naturais no bioma, principalmente dos recursos hídricos, tem comprometido as últimas reservas de fragmentos florestais que protegem a biodiversidade. No tocante à gestão de APs, em Brasília pode-se destacar a Reserva da Biosfera ${ }^{8}$ do Cerrado, composta pelo Parque Nacional de Brasília, a Estação Ecológica das Águas Emendadas e a APA do Gama e Cabeça de Veado. Entretanto, mais da metade dessas UCs ainda não foi implementada (Salles, 2008). Essa Reserva da Biosfera contempla uma rede de UCs localizadas no Distrito Federal e em municípios de Goiás, Tocantins, Maranhão e Piauí.

No Distrito Federal, assim como em diversas outras localidades no país, a ocupação irregular está entre os principais entraves que comprometem a conservação das UCs. Nessa direção, Salles (2008) frisa que nesse território existiam mais de 500 condomínios irregulares com aproximadamente 400 mil moradores, sendo que 75\% desses condomínios estavam localizados na APA do São Bartolomeu e na APA Bacia do Rio Descoberto, unidades inseridas em locais de beleza cênica e facilidade de acesso aos centros urbanos. O que torna a situação ainda mais grave é a falta de infraestrutura. Os moradores construíram fossas e perfuraram poços que comprometeram a qualidade das águas subterrâneas utilizadas. O autor menciona o caso da ocupação da Estrutural para exemplificar o agravamento das questões socioambientais, pois se iniciou:

com um grupo de pessoas que exploravam um lixão ao lado do Parque Nacional de Brasília no início dos anos 1990 e, hoje, com cerca de 35 mil habitantes, está em processo de regularização. Como se não bastasse o fato de ter, na área urbana, um lixão ${ }^{9}$, que recebe milhares de toneladas diárias de resíduos e está localizado a alguns metros dos limites do parque nacional, um poliduto da Petrobrás passa sob a Estrutural, expondo continuadamente a população a explosões e incêndios de grandes proporções (Salles, 2008, pp. 269-270).

É importante mencionar que há uma forte perspectiva para aumentar a produtividade nos solos nesse bioma. E as estatísticas evidenciam que a superfície agrícola pode aumentar em 42 milhões de hectares na próxima década, sendo cerca de metade no Brasil e Argentina (Food and Agriculture Organization of the United Nations [FAO], 2016). Com base nessas projeções, a América Latina será fonte de expansão da superfície agrícola do mundo, com um crescimento de $24 \%$ na área de cultivo, sendo a soja uma relevante impulsora e o Brasil o principal produtor em 2025 (Santos, 2018). Isso implica afirmar que esse bioma tende a continuar convivendo com a perda da biodiversidade em face da possível redução da quantidade e qualidade das UCs.

O agravamento das questões relacionadas também pode ser percebido em Águas Lindas de Goiás, considerada uma das cidades que mais cresceu no país nas últimas décadas.

8 Conceituada pela Lei do SNUC como "um modelo, adotado internacionalmente, de gestão integrada, participativa e sustentável dos recursos naturais, com os objetivos básicos de preservação da diversidade biológica, o desenvolvimento de atividades de pesquisa, o monitoramento ambiental, a educação ambiental, o desenvolvimento sustentável e a melhoria da qualidade de vida das populações" (Brasil, 2000).

9 O lixão mencionado por Salles (2008), conhecido como "Lixão Jóquei ou da Estrutural”, considerado o maior da América Latina e o segundo maior do mundo, funcionou por cerca de 50 anos (Fontes, 2016), sendo desativado apenas no início de 2018. 
A captação de água para abastecimento era realizada a partir da exploração do subsolo pelas companhias e pelos próprios moradores através de poços (Salles, 2008). Entretanto, o autor reforça que os resíduos sólidos e os efluentes domésticos sem tratamento são carreados para a barragem do Descoberto, localizada na APA Bacia do Rio Descoberto, o que compromete o manancial mais importante do Distrito Federal, visto que abastece $61,5 \%$ de sua população (Companhia de Saneamento Ambiental do Distrito Federal [CAESB], 2015).

Essa situação, de necessidade de proteção de mananciais, não é diferente nas UCs do Estado de Goiás, como é o caso do Parque Ecológico de Preservação Ambiental e Florestal Altamiro de Moura Pacheco (PEAMP), na Região Metropolitana de Goiânia (GO), Complexo de Chapadas de Goianápolis-Goiavista (Planalto dissecado), localizado na porção nordeste do município de Goianápolis. Essa UC, que dispõe de potencialidade turística, foi criada para proteger a biodiversidade e os recursos associados. Possui também patrimônio geomorfológico em cotas altimétricas entre $400 \mathrm{~m}$ e $1.200 \mathrm{~m}$, e contribui para a conservação de mananciais de corpos hídricos, como o Ribeirão João Leite, principal responsável pelo abastecimento de água para a Região Metropolitana de Goiânia (Campos \& Castro, 2006). Entretanto, também convivia com impactos ambientais como resultado das pressões na área do entorno do Parque, como crescimento urbano desordenado, desmatamentos próximos a cursos d'água, assoreamento intenso e contaminação dos mananciais superficiais por agrotóxicos (Campos, 2004).

Na Mata Atlântica, bioma historicamente devastado, a situação das UCs não é muito diferente, uma vez que, apesar da criação da Lei 11.428 de 2006 dispondo sobre a utilização e proteção da vegetação nativa do Bioma Mata Atlântica, ainda é frequente o desmatamento em suas áreas protegidas.

Nesse arcabouço, a relevância das UCs em prol da conservação e manutenção dos recursos naturais vem sendo evidenciada em diversas pesquisas. Um estudo divulgado pelo Ministério do Meio Ambiente ${ }^{10}$, realizado em parceria com o Programa das Nações Unidas para o Meio Ambiente (PNUMA), retrata que a criação e a manutenção das UCs no Brasil impediram a emissão de pelo menos 2,8 bilhões de toneladas de carbono, cujo valor monetário foi estimado em R $\$ 96$ bilhões. No tocante à energia elétrica, $80 \%$ é oriunda de hidrelétricas cujas fontes geradoras têm pelo menos um tributário a jusante de UCs. Quanto ao consumo de água, $9 \%$ é captada diretamente de UCs, $26 \%$ de fontes a jusante desses territórios, bem como $4 \%$ da água usada para agricultura é captada de fontes dentro ou a jusante de unidades. Os custos associados ao tratamento de água são menores nas bacias hidrográficas e nos mananciais quando comparados com as bacias que possuem baixa cobertura florestal.

As bacias hidrográficas, com cobertura vegetal conservada, oferecem água de melhor qualidade se comparadas com bacias hidrográficas submetidas a outros usos, como agricultura, indústria e assentamentos humanos, uma vez que a presença de florestas pode

10 Estudo desenvolvido pelo Centro para Monitoramento da Conservação Mundial do Programa das Nações Unidas para o Meio Ambiente (UNEP-WCMC) e pelo Ministério do Meio Ambiente, sob a coordenação técnica de pesquisadores da Universidade Federal Rural do Rio de Janeiro e da Universidade Federal do Rio de Janeiro, com o apoio técnico de GIZ e do IPEA, e o apoio financeiro do Department for Environment, Food and Rural Affairs (DEFRA). 
reduzir consideravelmente a necessidade de tratamento para água potável, o que resulta na diminuição dos custos associados ao tratamento da água. Aproximadamente um terço das maiores cidades do mundo obtém uma significativa proporção de água potável diretamente de áreas florestadas (Medeiros Young, Pavese, \& Araújo, 2011), inclusive no município de Campo Grande, onde parte da captação superficial de água para abastecimento local é realizada em UCs, na APA do Córrego Guariroba (34\%) e na APA do Lajeado (17\%) ${ }^{11}$. A existência de UCs em áreas urbanas e no seu entorno contribui para a estabilização do regime de precipitação de chuvas, ajuda a reter água no subsolo e a recarregar os aquíferos, comumente utilizados para captação de água.

Em termos numéricos, no Estado de São Paulo era captado um volume não sazonal anual de 18.043.481,5 $\mathrm{m}^{3}$ de água cujos pontos de captação estão localizados dentro de UCs, o que correspondia a uma vazão de $1.503 .623,5 \mathrm{~m}^{3} / \mathrm{mês}$. Considerando a tarifa mensal de $\mathrm{R} \$ 6,10$, a companhia gestora contabilizava uma arrecadação de $\mathrm{R} \$ 9.172 .103,118 /$ mês, dos quais $\mathrm{R} \$ 4.586 .051,6$ (50\%) eram atribuídos à presença de UCs que detinham pelo menos 65\% de cobertura florestal conservada (Medeiros, Young Pavese \& Araújo, 2011). De modo geral, quanto mais conservadas as UCs, menores serão os custos para o tratamento de água.

Por essa ótica, são inúmeros os desafios encontrados pelos gestores nas diferentes esferas governamentais na criação, implementação e gestão de UCs na Mata Atlântica e no Cerrado, pois, por um lado, tais interesses estão voltados para a utilização da natureza com fins mercadológicos cujas paisagens dotadas de beleza cênica e/ou com potencial hídrico, por exemplo, complementam os novos valores da biodiversidade enquanto capital natural. Por outro lado, apesar da importância dos recursos naturais, os impactos socioambientais associados ao desmatamento, às queimadas, à contaminação dos solos, do ar e dos recursos hídricos colocam em risco a conservação dos ecossistemas e comprometem a gestão dessas áreas e o modo de reprodução das populações envolvidas.

Nesse viés, mesmo após a criação de UCs, percebe-se a contínua degradação desses biomas. Assim, pode-se afirmar que o desenvolvimento da sociedade capitalista sem ocorrer a destruição da base biológica é sem dúvida um dos desafios a serem enfrentados no decorrer do século XXI (Silva, 2012), especialmente na gestão ambiental, ao lidar com o dilema da conservação ambiental versus usos dos territórios para alavancar a economia.

Entre os benefícios assegurados pelas UCs, é relevante reforçar os proveitos, tais como: parte significativa da qualidade e da quantidade da água que compõe os reservatórios de usinas hidrelétricas, que abastecem cidades e indústrias de energia (Medeiros, Young, Pavese, \& Araújo, 2011); a atividade turística, promovida pela mercantilização da natureza, usufruindo das paisagens de beleza cênica; o desenvolvimento da indústria de fármacos e cosméticos, entre outros. Entretanto, por se tratar de produtos e serviços em geral de natureza pública, prestados de forma difusa, seu valor não tem sido percebido pelos usuários. Observa-se que o papel das UCs não é facilmente 'internalizado' na economia, especialmente em função da falta de informações sistematizadas capazes de esclarecer à sociedade a relevância do papel delas no fornecimento de bens e serviços que

11 Águas Guariroba (2018). Disponível em: <http://www.aguasguariroba.com.br/agua/>. 
contribuem para o desenvolvimento socioeconômico do país (Medeiros, Young, Pavese \& Araújo, 2011).

Medeiros, Young, Pavese e Araújo (2011) assinalam ainda que, apesar das várias funções ofertadas pelas UCs, parte dos lucros advindos da exploração dos recursos naturais nesses territórios não tem sido destinada à conservação das unidades, embora isso seja previsto nos Artigos 47 e 48 do SNUC:

Art. 47. O órgão ou empresa, público ou privado, responsável pelo abastecimento de água ou que faça uso de recursos hídricos, beneficiário da proteção proporcionada por uma unidade de conservação, deve contribuir financeiramente para a proteção e implementação da unidade, de acordo com o disposto em regulamentação específica.

Art. 48. O órgão ou empresa, público ou privado, responsável pela geração e distribuição de energia elétrica, beneficiário da proteção oferecida por uma unidade de conservação, deve contribuir financeiramente para a proteção e implementação da unidade, de acordo com o disposto em regulamentação específica.

Nessa análise, é importante mencionar que o repasse dos lucros pelas empresas que usam esses territórios é uma estratégia fundamental para garantir a sustentabilidade econômica, social e ambiental das UCs.

\section{ÁREAS DECRETADAS COMO UCS: A PROLIFERAÇÃO DA CATEGORIA ÁREA DE PROTEÇÃO AMBIENTAL NOS BIOMAS NACIONAIS E O DILEMA DOS HOTSPOTS}

Em virtude das características, dos usos atribuídos aos territórios e por não haver necessidade de desapropriação fundiária, as esferas federal, estadual e municipal têm optado pela criação de APA. A proliferação dessa categoria está relacionada às diferenças nos custos que envolvem o processo de criação e implementação, uma vez que são inferiores quando comparados com os gastos com outras categorias do SNUC que necessitam de desapropriação fundiária (Silva \& Souza, 2013). Ademais, teoricamente tendem a "gerar menos conflitos" quando contrastadas com as categorias que necessitam de desapropriação fundiária, porém nem sempre tem garantido sua conservação. Nesse sentido, no caso dessa categoria, pode-se afirmar que os desafios para garantir a conservação são ainda maiores, pois se trata de unidades que já nascem permeadas por usos diversos e por impactos socioambientais que dificultam a gestão ambiental.

Essas unidades têm sido consideradas como inoperantes (Oliveira, 2017; Dourojeanni \& Pádua, 2013; Silva, 2012), pois nem sempre cumprem as finalidades ecológicas pelas quais foram criadas, principalmente devido à deficiência no planejamento e na gestão ambiental; à ausência de instrumentos técnicos, como plano de manejo, zoneamento ecológico econômico e programas de EA crítica; à escassez de recursos financeiros e quadro humano reduzido; aos interesses pelo uso, controle e apropriação dos recursos naturais, entre outros motivos. A falta de instrumentos capazes de ordenar o uso do território acaba facilitando a dilapidação dos recursos naturais, bem como a eclosão de conflitos antes mesmo da implementação (Silva, 2012). 
Até 2017, em âmbito nacional, foram decretados $2.544 .917 \mathrm{~km}^{2}$ como UCs, ou seja, $30 \%$ do território nacional. Do total da extensão territorial, $26 \%$ pertenciam ao grupo de Proteção Integral e 74\% às UCs de Uso Sustentável (Tab. 1) (MMA/CNUC, 2018a). Contudo, sabe-se que essa porcentagem está muito aquém do que de fato essas unidades conservam da biodiversidade in loco. O Brasil teve um significativo aumento na criação de UCs, todavia "há um grande passivo na consolidação das unidades existentes" (Prates \& Souza, 2014, p. 97).

Com relação à análise por biomas, em 2011 constatou-se que na Caatinga ${ }^{12}$, Cerrado e Mata Atlântica, a área destinada às categorias de UCs dos dois grupos era inferior a 7\% em cada território. Esse valor pode ser ainda menor devido ao processo de desmatamento e ocupação desordenada nessas unidades. Já as UCs do Pantanal e Pampa não atingiram 3\% da área destinada à conservação (MMA/CNUC, 2011), ficando abaixo da média mundial de 5\% (IBGE, 2010). A Amazônia era o único bioma com 23,8\% da extensão territorial na condição de UCs (MMA/CNUC, 2011).

Conforme a Tabela 1, em 2018, embora os valores ainda sejam modestos, a Amazônia ampliou sua área protegida para 28,1\%; o Cerrado e Caatinga para 9\%; e a Mata Atlântica chegou a $9,4 \%$. Já o Pantanal e o Pampa continuaram abaixo de $5 \%$, com apenas $4,6 \%$ e $2,9 \%$, respectivamente, considerando-se as áreas sobrepostas (MMA/CNUC, 2018b ${ }^{13}$ ). Apesar do reconhecimento incontestável sobre sua diversidade biológica, o Cerrado e a Mata Atlântica, os dois hotspots brasileiros, possuíam apenas 3,2\% e 2,6\%, respectivamente, de suas áreas sob Proteção Integral. Contudo, com exceção da Amazônia (com 10,2\%), a área integralmente protegida nos demais biomas também é muito pequena, variando entre 0,5\% (Pampa) e 2,9\% (Pantanal). Ou seja, além dos entraves que fragilizam a conservação, a cobertura de áreas oficialmente protegidas ainda é pequena para todos os biomas, independentemente de sua relevância para a conservação ambiental.

Na Tabela 2, observa-se que, no grupo de Proteção Integral prioriza-se a categoria Parque nas três esferas administrativas. Do total da área de $663.716 \mathrm{~km}^{2}$, constatou-se que $54,7 \%$ se referem a 425 Parques (MMA/CNUC, 2018a) nos diversos biomas. Essa categoria prevê desapropriação e convive com inúmeros conflitos, pois exclui as comunidades que residiam nas localidades ao mesmo tempo em que a utilizada para o turismo. Entretanto, vários Parques nasceram no bojo de graves pendências fundiárias que estão longe de resolução (Silva \& Souza, 2012). Como exemplo, pode-se citar o PARNA de Itatiaia, criado em 1937, na divisa dos Estados de Minas Gerais e do Rio de Janeiro, o qual apenas em 2016 obteve $51 \%$ da área regularizada (MMA/ICMBIO, 2016), entre muitos outros que poderiam ser citados.

No que concerne ao valor total da área "decretada para conservação" do país, 1.881.201 $\mathrm{km}^{2}$, considerando-se as sete categorias de UCs do grupo de Uso Sustentável, boa parte da área pertencia às APAs, com $68,8 \%$ do território, conforme Tabela 2 (MMA/ CNUC, 2018a). No tocante às análises das esferas gestoras, até julho de 2018, a partir da

12 Considerado o bioma semiárido mais rico do mundo em biodiversidade (Zanirato, 2010).

13 Foram desconsideradas as áreas sobrepostas nos referidos biomas. 
Tabela 1 pôde-se constatar que, dos $1.216 .348 \mathrm{~km}^{2}$ que englobavam as categorias de Uso Sustentável, sob gestão do ICMBio, 73,8\% pertenciam à categoria APA; $55,9 \%$ na esfera estadual, e incríveis $99,5 \%$ na esfera municipal.

No que diz respeito aos biomas (Tab. 1), na análise das categorias de Uso Sustentável no Cerrado, do total de 5,5\% do território destinado no grupo, 5,4\% da extensão territorial pertenciam à categoria $\mathrm{APA}$, ou seja, $112.811 \mathrm{~km}^{2}$ da área. $\mathrm{E}$, dos $7,8 \%$ do mesmo grupo no bioma Mata Atlântica, 7,5\% também pertenciam à categoria de APA (MMA/CNUC, 2018b). Os dados evidenciam que, 96,8\% do território de Cerrado decretado em UCs pertenciam à categoria APA, enquanto no bioma Mata Atlântica esta categoria compõe 96,6\% da extensão territorial (MMA/CNUC 2018b). Ou seja, apesar da importância mundial dos dois biomas, de sua relevância para a conservação da biodiversidade, eles são pouco representados e convivem com o dilema dos usos e conservação.

Os números referentes às APAs não são diferentes nos demais biomas, com 97,9\% de presença na Caatinga e 99,9\% no Pampa. Exceção apenas ao Pantanal, que de acordo com a Tabela 1 possuía somente RPPNs, e da Amazônia, com 39,3\% da área decretada como APA. 
Tabela 1: Unidades de Conservação de Uso Sustentável por bioma até julho de 2018.

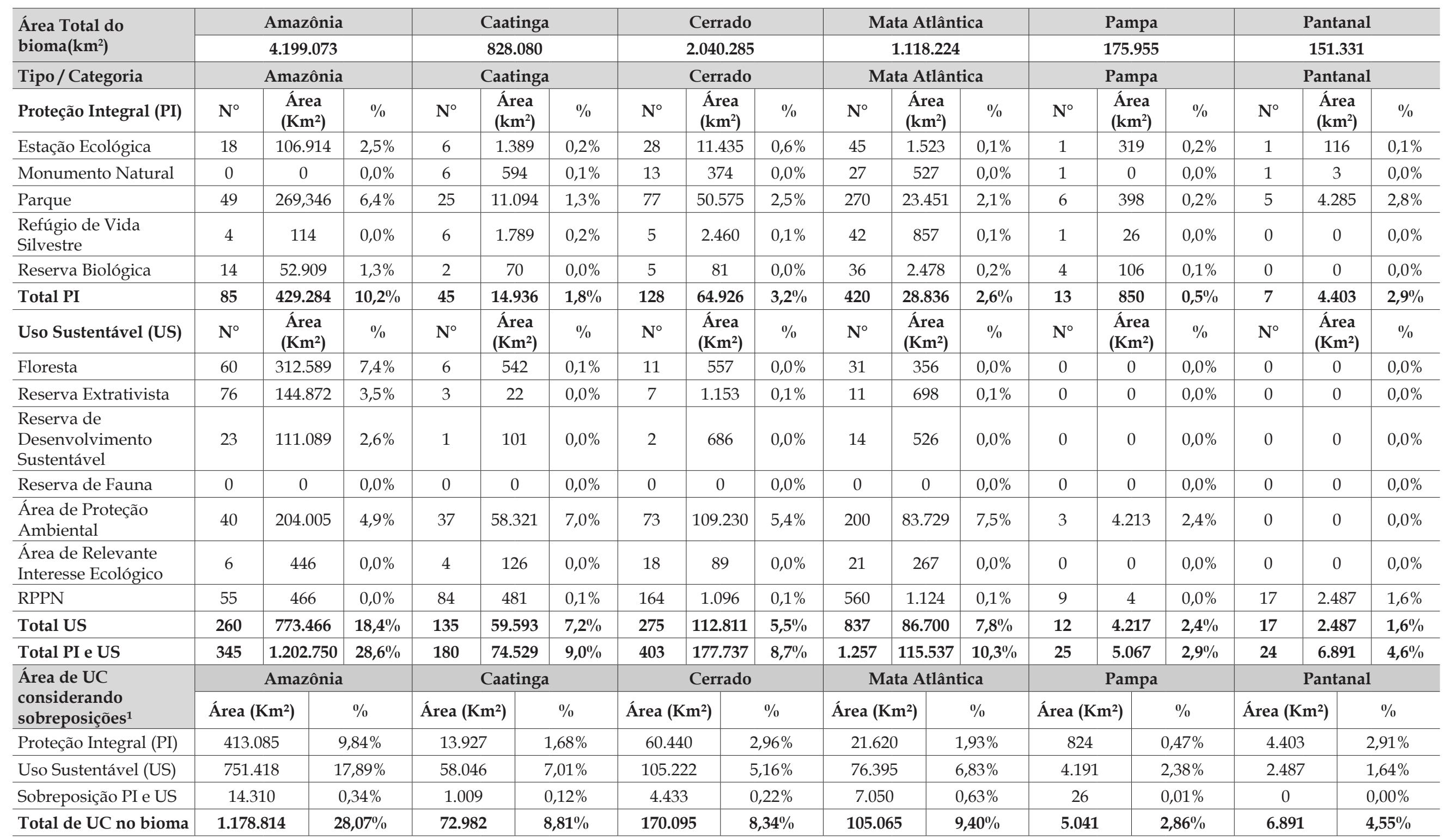

${ }^{1}$ As áreas de sobreposição consideradas foram obtidas a partir dos arquivos com dados espaciais cadastrados e validados no CNUC.

Fonte: MMA/CNUC, 2018b. Disponível em: <http://www.mma.gov.br/images/arquivo/80229/CNUC_JUL18\%20-\%20C_Bio.pdf>. 
Tabela 2: Áreas nos Biomas brasileiros protegidos por UCs nas esferas administrativas em 2018.

\begin{tabular}{|c|c|c|c|c|c|c|c|c|}
\hline \multirow{3}{*}{$\begin{array}{l}\text { Tipo/Categoria } \\
\text { Proteção Integral }\end{array}$} & \multicolumn{6}{|c|}{ Esfera } & \multirow{2}{*}{\multicolumn{2}{|c|}{ TOTAL }} \\
\hline & \multicolumn{2}{|c|}{ Federal } & \multicolumn{2}{|c|}{ Estadual } & \multicolumn{2}{|c|}{ Municipal } & & \\
\hline & $\mathbf{N}^{\circ}$ & Área $\left(\mathbf{K m}^{2}\right)$ & $\mathbf{N}^{\circ}$ & Área $\left(\mathrm{Km}^{2}\right)$ & $\mathbf{N}^{\circ}$ & Área $\left(\mathrm{Km}^{2}\right)$ & $\mathbf{N}^{\circ}$ & Área $\left(\mathrm{Km}^{2}\right)$ \\
\hline Estação Ecológica & 31 & 74.302 & 62 & 47.507 & 5 & 40 & 98 & 121.849 \\
\hline Monumento Natural & 5 & 115.405 & 29 & 906 & 16 & 151 & 50 & 116.461 \\
\hline $\begin{array}{l}\text { Parque Nacional / Estadual / } \\
\text { Municipal }\end{array}$ & 74 & 268.212 & 209 & 94.229 & 142 & 651 & 425 & 363.092 \\
\hline Refúgio de Vida Silvestre & 9 & 2.984 & 45 & 2.947 & 8 & 175 & 62 & 6.107 \\
\hline Reserva Biológica & 31 & 42.668 & 24 & 13.488 & 8 & 51 & 63 & 56.207 \\
\hline Total Proteção Integral & 150 & 503.571 & 369 & 159.077 & 179 & 1.068 & 698 & 663.716 \\
\hline Uso Sustentável & $\mathbf{N}^{\circ}$ & Área $\left(\mathrm{Km}^{2}\right)$ & $\mathbf{N}^{\circ}$ & Área $\left(\mathrm{Km}^{2}\right)$ & $\mathbf{N}^{\circ}$ & Área $\left(\mathrm{Km}^{2}\right)$ & $\mathbf{N}^{\circ}$ & Área $\left(\mathrm{Km}^{2}\right)$ \\
\hline $\begin{array}{l}\text { Floresta Nacional / Estadual / } \\
\text { Municipal }\end{array}$ & 67 & 178.187 & 39 & 135.857 & 0 & 0 & 106 & 314.044 \\
\hline Reserva Extrativista & 66 & 134.833 & 28 & 19.845 & 0 & 0 & 94 & 154.677 \\
\hline $\begin{array}{l}\text { Reserva de Desenvolvimento } \\
\text { Sustentável }\end{array}$ & 2 & 1.026 & 32 & 111.251 & 5 & 171 & 39 & 112.447 \\
\hline Reserva de Fauna & 0 & 0 & 0 & 0 & 0 & 0 & 0 & 0 \\
\hline Área de Proteção Ambiental & 37 & 897.088 & 190 & 339.418 & 99 & 56.930 & 326 & 1.293 .435 \\
\hline Área de Relevante Interesse Ecológico & 13 & 341 & 26 & 455 & 11 & 140 & 50 & 936 \\
\hline RPPN & 663 & 4.873 & 224 & 787 & 1 & 0 & 888 & 5.661 \\
\hline Total Uso Sustentável & 848 & 1.216 .348 & 539 & 607.613 & 116 & 57.240 & 1503 & 1.881 .201 \\
\hline Total Geral & 998 & 1.719 .919 & 908 & 766.690 & 295 & 58.308 & 2201 & 2.544 .917 \\
\hline $\begin{array}{l}\text { Área Considerando Sobreposição } \\
\text { Mapeada }\end{array}$ & 998 & 1.713 .973 & 908 & 760.387 & 295 & 58.243 & 2201 & 2.498.195 \\
\hline
\end{tabular}

Fonte: MMA/CNUC, 2018a. Disponível em: <http://www.mma.gov.br/images/arquivo/80229/ CNUC_JUL18\%20-\%20B_Cat.pdf $>$.

No que concerne à análise sobre a efetividade das UCs federais, a segunda aplicação do Sistema de Análise e Monitoramento da Gestão de UC ${ }^{14}$ (SAMGe), em 2016, compreendeu 320 unidades federais, com 168 gestores de UCs respondentes e 156 unidades de efetivo preenchimento, equivalente a 48,6 das UCs federais (MMA/ICMBIO, 2017). Na análise dos 101 alvos de conservação identificados na categoria APA, 35,7\% foram considerados alvos em estado de manutenção, atendendo aos princípios de conservação esperados. Entretanto, foram apontados 65 alvos de intervenção, ou seja, 64,4\% das APAs analisadas convivem com vários impactos socioambientais que comprometem a conservação da biodiversidade ao longo do tempo (MMA/ICMBIO, 2017).

Por conseguinte, em virtude dos desafios enfrentados na gestão ambiental das UCs no contexto nacional e de interesses diversos, também têm sido frequentes na literatura questionamentos relacionados ao papel das APAs na conservação ambiental. Na prática, essa concepção tem implicado a inoperância dessa categoria, cujos recursos naturais acabam sendo dilapidados antes mesmo de sua implementação. Nesse contexto, para Dourojeanni e Pádua: 
As APAs são "unidades de conservação" quase sem valor ambiental. Nelas os proprietários podem fazer tudo o que se faz em qualquer outro canto do país, inclusive plantar extensas monoculturas. O poder público só pode fazer cumprir a lei orgânica que se aplica em outros lugares, pois as terras, em geral, estão em mãos de particulares (2013, p. 143).

Com relação à Amazônia, 40,4\% das áreas protegidas pertencem à categoria FLONA (MMA/CNUC, 2018b). Ou seja, reforça-se o dilema da conservação versus exploração florestal e usos diversos nos territórios legalmente protegidos. Isso, por sua vez, fortalece a ideia de que, em muitos casos, as UCs são criadas para resguardar territórios para usos futuros, como ressalta Silva (2012). Exemplificando, entre setembro de 2008 e novembro de 2019, foram assinados:

dezessete contratos de concessão florestal federal no âmbito do Serviço Florestal Brasileiro (SFB): dois na Flona do Jamari (RO), quatro na Flona Saracá-Taquera (PA), dois na Flona de Jacundá (RO), dois na Flona do Crepori (PA), quatro na Flona de Altamira (PA) e três na Flona de Caxiuanã (PA). Destes 17 contratos, os dois da Flona Crepori estão suspensos por determinação judicial e um, na Flona de Saracá-Taquera, por decisão administrativa (MMA/SBF, 2018, p. 33).

O mesmo relatório apresenta que os valores de referência desses contratos variaram entre $\mathrm{R} \$ 434.865,78$, na FLONA Altamira, e R $\$ 6.750 .621,67$, na FLONA Caxiuanã, ambas no Estado do Pará (MMA/SBF, 2018). O que, certamente, tende a se agravar em face das deficiências no processo de monitoramento das FLONAS, após aprovação da Lei 11.284/2006.

Nesse arcabouço, a título de exemplo, vale mencionar que além dos desafios para a implementação, gestão e conservação das unidades na prática, a área destinada à conservação $(28,07 \%)$ ainda está abaixo da meta pretendida de $30 \%$ para o bioma. Logo, isso merece ser revisado devido às potencialidades encontradas nesse bioma, mundialmente reconhecido, pois abriga aproximadamente $30 \%$ da diversidade biológica mundial representada em suas florestas. Ademais, a bacia do rio Amazonas é responsável por cerca de $20 \%$ da água doce (não congelada) do planeta e $80 \%$ da água disponível no território brasileiro (Brasil, 2008).

No bioma Amazônia, o processo de aceleração da erosão da biodiversidade já é consenso internacional, evidenciando, de um lado, aqueles interessados na conservação da biodiversidade devido aos lucros propiciados, como a indústria da biotecnologia, principalmente da farmacologia, e, do outro, os atores sociais que têm suas fontes de riqueza originárias da exploração predatória dos recursos naturais, como o setor agropecuário, as empresas madeireiras e mineradoras e o segmento ligado ao turismo. Retruca-se, desse modo, o dilema da conservação atrelado à manutenção da "floresta de pé" versus usos diversos. Esse processo também é realidade nos demais biomas, o que amplia os embates entre os atores sociais que lutam pela "floresta viva" e aqueles que têm interesse no avanço da soja, da agropecuária, da exploração mineral e na implantação de infraestrutura para as atividades turísticas, como ocorre no Pantanal e na Mata Atlântica.

Nessas análises, as assertivas de Albagli (1998) corroboram os conflitos engendrados na Floresta Amazônica, em função dos milhões de dólares originários da exportação de 
madeiras nobres e de minérios versus os bilhões de dólares, como resultado das combinações genéticas da floresta, as quais têm despertado o interesse de atores sociais ligados tanto à conservação ambiental quanto à exploração predatória. Tais premissas, na contemporaneidade, estão cada vez mais notáveis, independentemente do bioma.

Para Bensusan (2014, p. 49), a gestão ambiental tem se revelado "um instrumento de conservação com um certo grau de perversidade, permitindo assim um uso intenso, e por vezes predatório, do resto do território enquanto, logra no máximo, proteger elementos da biodiversidade por um intervalo de tempo limitado". Nesse sentido, o dilema da gestão ambiental em UCs está imbricado em relações conflitivas que permeiam as arenas políticas, sociais, culturais, econômicas e ambientais que comprometem a conservação desses territórios, cujas florestas, responsáveis pela manutenção da biodiversidade, estão cada vez mais fragmentadas. Assim, os desafios também estão arraigados à necessidade de estratégias para avançar na gestão participativa, as quais, para além da área da UC, precisam considerar os territórios circunvizinhos, bem como a permanência das comunidades locais que dependem e necessitam da manutenção desses espaços. Tais ações precisam considerar as especificidades, potencialidades e vulnerabilidades dos biomas nacionais e os modos e histórias de vida das comunidades tradicionais e locais.

Embora os benefícios das UCs sejam incalculavéis, e, apesar do avanço no arcabouço jurídico no Brasil, percebe-se o aumento da quantidade de APAs, uma categoria que na prática não tem garantido a conservação em face dos desafios na gestão ambiental. Para a conservação desses espaços, as estratégias de gestão ambiental devem priorizar a visão sistêmica, considerando-se os fatores biofísicos associados aos aspectos climáticos, geológicos, geomorfológicos, pedológicos, hidrológicos e humanos das UCs e seu entorno. Isso demanda uma gestão ambiental participativa capaz de envolver os diversos segmentos da sociedade para assegurar a participação efetiva das populações locais na criação, implantação e gestão das UCs, como previsto no parágrafo III do Art. 5o do SNUC.

Torna-se fundamental, portanto, a execução de estratégias respaldadas na Educação Ambiental crítica, visto seu caráter emancipatório que implica em mudanças individuais e coletivas (Loureiro, 2004). Uma vez que estimula a cidadania, esta desperta o sentimento de pertencimento e corresponsabilidade para a busca coletiva da compreensão e superação das causas dos problemas socioambientais (Sorrentino, Trajber, Mendonça, \& Ferraro Junior, 2005). Assim, pode fornecer subsídios para a solução ou mediação dos problemas e conflitos a partir de processos de ensino e aprendizagem em espaços formais ou não formais, vislumbrando a construção de conhecimentos e a formação de uma cidadania ambiental (Carvalho, 2004).

\section{CONSIDERAÇÕES FINAIS}

As UCs são criadas como estratégia de gestão ambiental no contexto nacional, entretanto não têm conseguido promover a conservação da biodiversidade nos biomas nacionais, especialmente naqueles considerados hotspots, como a Mata Atlântica e o Cerrado, 
e nos demais biomas que apresentam áreas consideradas Grande Regiões Naturais, como Amazônia, Pantanal e Caatinga, em virtude do processo intenso de desmatamento para atender às demandas socioeconômicas em detrimento da perda da biosociodiversidade.

As informações do CNUC evidenciam que cerca de $30 \%$ da extensão territorial encontra-se decretado sob forma de UC. No entanto, faz-se necessária a revisão de boa parte dessas unidades, pois, além da existência de várias outras áreas consideradas prioritárias para a conservação, na prática os órgãos gestores encontram dificuldades para efetivar a conservação e manutenção da biodiversidade e de fatores físicos associados.

Os dados do CNUC também mostram que boa parte das UCs se encontra direcionada para uma categoria que, pelo histórico do país, não garante a conservação, a APA. Esta categoria tem mostrado pouca eficiência na manutenção e conservação diante dos múltiplos usos estabelecidos nos territórios, dos conflitos socioambientais, das ausências e/ou deficiências na elaboração e da aplicação de instrumentos de gestão ambiental. É pertinente um processo de avaliação quanto à priorização desta categoria no modelo de gestão ambiental adotado. Essa revisão, e quiçá recategorização, de parte das APAs, precisa considerar os recursos naturais, os atores sociais, os usos estabelecidos e os conflitos desencadeados rumo a uma gestão participativa que permita minimizar os efeitos dos dilemas da conservação.

Igualmente, é primordial reavaliar a concessão florestal, especialmente no bioma Amazônia, em virtude da relevância da biodiversidade e dos serviços ambientais ofertados pelas florestas em escala local, nacional e planetária.

Nesse cenário, torna-se fundamental encontrar soluções de ordem política, econômica e prática para minimizar os graves problemas percebidos, sentidos e vividos nos biomas nacionais. Assim, urge a criação e implementação de mecanismos de gestão ambiental, como: plano de gestão e de manejo; zoneamento ecológico econômico; elaboração e aplicação de programas de EA crítica. Igualmente, a identificação dos atores sociais e dos tipos de conflitos favorecerá

O conjunto de Áreas Protegidas precisa desconsiderar o mito da natureza intocada e incluir os diversos atores sociais identificados na gestão ambiental participativa, na criação de estratégias capazes de mediar os conflitos existentes e evitar que atinjam patamares mais elevados e as comunidades locais e povos tradicionais possam usufruir dos bens e serviços ambientais proporcionados.

A criação, o fortalecimento e a qualificação dos Conselhos Gestores na gestão ambiental também podem contribuir para o diálogo direcionado tanto à mediação dos conflitos quanto à criação e implementação de políticas públicas eficientes e eficazes para esses territórios. Ademais, torna-se primordial: estabelecer parcerias entre os setores públicos e privados; estimular a criação de RPPN e/ou outras categorias de UCs de Uso Sustentável e demais Áreas Protegidas; criar e implementar estratégias para pagamentos de serviços ambientais, já que boa parte das APAs compreende propriedades privadas; aumentar e direcionar os recursos financeiros e humanos nas UCs; criar estratégias para estabelecer a conectividade, via corredores ecológicos, que permitam a troca de material 
genético entre as espécies para reduzir os efeitos da formação de 'ilhas de vegetação' e o isolamento dos fragmentos.

Por fim, há a necessidade de avançar priorizando-se a Educação Ambiental no processo de gestão como estratégia na divulgação da relevância da conservação desses espaços e dos serviços ambientais prestados. É a partir da EA que se pode contribuir na conservação e restauração in loco, na mediação dos conflitos e na defesa daqueles que sofrem os efeitos das injustiças ambientais.

\section{REFERÊNCIAS}

Ab'Saber, A.N. (2003). Os Domínios de Natureza no Brasil: potencialidades paisagísticas. São Paulo: Ateliê Editorial.

Acselrad, H. (2004). As práticas espaciais e o campo dos conflitos ambientais. In H. Acselrad (Org). Conflitos ambientais no Brasil. Rio de Janeiro: Relume Dumará.

Acselrad, H., Melo, C.C.A., \& Bezerra, C.N. (2009). O que é Justiça Ambiental. Rio de Janeiro: Garamond.

Albagli, S. (1998). Geopolitica da biodiversidade. Brasília: Ed. IBAMA.

Alves, S.G., \& Santos, S.L. (2017). Injustiças e conflitos socioambientais: o que são e como surgem? Rev. Revista Gestão e Sustentabilidade Ambiental (RG\&AS), 6(2): 216-226.

Alves, G.H.Z. et al. (2019). Misguided policy may jeopardize a diverse South Brazilian environmental protection area. Biota Neotrop., 19(1): e20180574. http:/ / dx.doi.org/10.1590/1676-0611-BN-2018-0574

Assoni, C. (2007). Impactos ambientais negativos causados por atividades turísticas no Morro do Cuscuzeiro. (Monografia de Conclusão de Curso de Turismo). Centro Universitário Central Paulista, UNICEP, São Carlos, SP, Brasil.

Bayma, A.P., \& Sano, E.E. (2015). Séries temporais de índices de vegetação (NDVI e EVI) do sensor modis para detecção de desmatamentos no bioma Cerrado. Boletim de Ciências Geodésicas, 21(4): 797-813.

Bensusan, N. (2014). Diversidade e unidade: um dilema constante. Uma breve história da ideia de conservar a natureza em Áreas Protegidas e seus dilemas. In N. Bensusan, \& A.P. Prates (Orgs.) A diversidade cabe na Unidade? Áreas Protegidas no Brasil. (pp. 30-81). Brasília: IEB.

Botelho, R.G.M. (2010). Território e Meio Ambiente: Recursos naturais e questões ambientais. In Atlas Nacional do Brasil Milton Santos. Diretoria de Geociências. (pp. 68-97). Rio de Janeiro: IBGE. Recuperado de https://biblioteca.ibge.gov.br/visualizacao/livros/liv47603_cap4_pt8.pdf.

Campos, A.C. (2004). Degradação ambiental em Unidades de Conservação Estaduais: o caso do Parque Ecológico Altamiro de Moura Pacheco e seu entorno. (Dissertação de Mestrado em Geografia). Universidade Federal de Goiás, UFGO, Goiânia, GO, Brasil.

Campos, A.C., \& Castro, S.S. (2006). Patrimônio Geomorfológico em Unidades de Conservação de Proteção Integral: o caso do parque ecológico de Preservação Ambiental e Florestal Altamiro de Moura Pacheco (PEAMP), Região Metropolitana de Goiânia (GO). Simpósio Nacional De Geomorfologia / Regional Conference On Geomorphology. Goiânia, GO, Brasil, 1. (pp. 1-9) Recuperado de http://lsie.unb.br/ugb/ sinageo/6/13/520.pdf.

Carmo, J.P.A. (2009) Analândia/SP: desenvolvimento da indústria do turismo e implicações ambientais. Caminho da Geografia, 10(32):113-126.

Carvalho. I.C.M. (2004). Educação Ambiental Crítica: nomes e endereçamentos da educação. In P.P. Layrargues. Identidades da Educação Ambiental brasileira. (pp. 13-24). Brasília: MMA.

Coelho, M.C.N., Cunha, L.H., \& Monteiro, M.A. (2009). Unidades de Conservação: populações, recursos e territórios. Abordagens da Geografia e da Ecologia Política. In A.J.T. Guerra, \& M.C.N. Coelho (Orgs.) Unidades de Conservação: Abordagens e características Geográficas. (pp. 67-111). Rio de Janeiro: Bertrand Brasil. 
CompanhiadeSaneamentoAmbientaldoDistritoFederal(2015). Estudo.LevantamentodasituaçãoatualdoParque Estadual do descoberto. Águas Lindas de Goiás/GO. Ocupações Irregulares, Uso do Solo e Importância da Implantação. Brasília. Recuperado de http://www.mpgo.mp.br/portal/arquivos/2016/03/08/11_56_27_944_ ESTUDO_TEC_001_2015_Parque_Estadual_Descoberto.pdf.

Conservação Internacional. (2018). Hotspots revisados: as regiões biologicamente mais ricas e ameaçadas do planeta. Recuperado de https://www.conservation.org/global/brasil/publicacoes/Documents/ HotspotsRevisitados.pdf.

Diegues, A.C.S. (2008). O mito moderno da natureza intocada. 6.ed. ampl. São Paulo: HUCITEC/ NUPAUBUSP/CEC. Recuperado de http://www.florestal.gov.br/documentos/publicacoes/3531-relatorio-degestao-de-florestas-publicas-2017/file.

Dourojeanni, M.J., \& Pádua, M.T.J. (2013). Arcas à deriva: unidades de conservação no Brasil. Rio de Janeiro: Technical Books.

Drummond, G.M., \& Antonini, Y. (2006). A contribuição da Fundação Biodiversitas para implementação do artigo $7^{\circ}$ da Convenção sobre Diversidade Biológica. In: N. Bensusan et al. (Orgs.) Biodiversidade: para comer, vestir ou passar no cabelo? Para mudar o mundo! (pp. 31-48). São Paulo, Peirópolis.

Durigan, G., Melo, A.C.G., Max, J.C.M., Vilas Boa, O., Contieri, W.A., \& Ramos, V.S. (2011). Manual para recuperação da vegetação de cerrado. São Paulo: SMA.

Empresa Brasileira de Pesquisa Agropecuária. Biodiversidade do bioma cerrado. Recuperado de http:/ / www. agencia.cnptia.embrapa.br/Agencia16/AG01/arvore/AG01_2_111200610412.html.

Fontes, T.O.C. (2016). Fortalezas e fragilidades da transferência do Aterro Controlado do Jóquei para o Aterro Sanitário de Brasília. (Monografia). Universidade de Brasília, UnB, Brasília, DF, Brasil. Recuperado de http://bdm.unb.br/bitstream/10483/15201/1/2016_TatianaOliveiraChavesFontes_tcc.pdf.

Food and Agriculture Organization of the United Nations (2016). Global Forest Resources Assessment 2015: How are the world's forest changing? 2.ed. Rome.

Ganem, R.S. (2015). Pagamento por serviços ambientais com recursos públicos com base em Área de Preservação Permanente e Reserva Legal. Nota Técnica. Distrito Federal: Consultoria Legislativa. Recuperado de http:// www2.camara.leg.br/a-camara/documentos-e-pesquisa/estudos-e-notas-tecnicas/areas-da-conle/ tema14/2015_18190_pgt-servicos-ambientais_roseli-ganem.

Greenpeace. Desmatamento no Cerrado aumentou 9\% no último ano. Recuperado de https:/ / www.greenpeace. org/brasil/blog/desmatamento-no-cerrado-aumentou-9-no-ultimo-ano/?gclid=CjwKCAjwtvnbBRA5Ei wAcRvnpkLMzPtwvz71OzQFsQf22D_nIDM5iKnZEwclFc6w9m1m9-EZHBH-qBoCxXsQAvD_BwE.

Guimarães, A.L. (2005). O desafio de conservar e recuperar a Mata Atlântica: construindo corredores de biodiversidade. In E. Batista, R.F. Cavalcanti, \& . R.F. Fujihara (Org.) Caminhos da Sustentabilidade no Brasil. São Paulo: Terra das Artes.

Instituto Brasileiro de Geografia e Estatística. (2010). IDS 2010: país evolui em indicadores de sustentabilidade, mas ainda há desigualdades socioeconômicas e impactos ao meio ambiente. Brasília. Recuperado de http://www. ibge.gov.br/home/presidencia/noticias/noticia_visualiza.php?id_noticia=1703\&id_pagina=1.

Instituto Nacional de Pesquisas Espaciais. (2019a). A área de vegetação nativa suprimida no Bioma Cerrado no ano de 2019 foi de $6.484 \mathrm{~km}^{2}$. São José dos Campos. Recuperado de http://www.inpe.br/noticias/ noticia.php?Cod_Noticia $=5320 \#: \sim$ :text $=$ O $\% 20$ Minist $\%$ C3 $\%$ A9rio $\% 20 \mathrm{da} \% 20 \mathrm{Ci} \%$ C3 $\%$ AAncia $\% 2$ C $\% 20$ Tecnologia,2018\%20a\%20julho\%20de\%202019.

Instituto Nacional de Pesquisas Espaciais. (2019b). SOS Mata Atlântica e INPE lançam novos dados do Atlas do bioma. São José dos Campos. Recuperado de: http://www.inpe.br/noticias/noticia.php?Cod_ Noticia $=5115$.

Klink, C.A., \& Machado, R.B. (2005). Conservation of the Brazilian Cerrado. Conservation Biology, 19(3):707-713.

Layrargues, P.P. (2000). Educação para gestão ambiental: a cidadania no enfrentamento político dos conflitos socioambientais. In C.F.B., Loureiro, P.P. Layrargues, \& R.S. Castro (Orgs.). Sociedade e Meio Ambiente: a educação ambiental em debate. (pp. 87-155). São Paulo: Cortez. 
Lei $\mathrm{n}^{0} 11.428$, de 22 de dezembro de 2006. Dispõe sobre a utilização e proteção da vegetação nativa do Bioma Mata Atlântica, e dá outras providências. Recuperado de http:/ / www.planalto.gov.br/ccivil_03/_ ato2004-2006/2006/lei/111428.htm.

Leuzinger, M.D. (2007). Natureza e Cultura, direito ao meio ambiente equilibrado e direitos culturais diante da criação de Unidades de Conservação de Proteção Integral e o domínio público habitadas por populações tradicionais. (Tese de Doutorado em Desenvolvimento Sustentável). Universidade de Brasília, UnB, Brasília, DF, Brasil.

Loureiro, C.F.B. (2004). Educação ambiental e gestão participativa na explicitação e resolução de conflitos. Gestão em Ação, 7(1):37-50.

Medeiros, R., Young, C.E.F, Pavese, H.B., \& Araújo, F.F.S. (2011). Contribuição das Unidades de Conservação brasileiras para a economia nacional: Sumário Executivo. Brasília: UNEP-WCMC e MMA.

Mesquita, C.A.B., Cole, A.S., \& Leite, A. (2006). O papel do setor florestal na conservação da biodiversidade da Mata Atlântica. In: N. Bensusan, et al. (Orgs.) Biodiversidade: para comer, vestir ou passar no cabelo? Para mudar o mundo! (pp. 175-193). São Paulo, Peirópolis.

Ministério de Meio Ambiente/SBF (2002). Biodiversidade brasileira: avaliação e identificação de áreas e ações prioritárias para conservação, utilização sustentável e repartição dos benefícios da biodiversidade nos biomas brasileiros. Brasília. Recuperado de www.mma.gov.br/probio/publicações/biodiversidade5.

Ministério de Meio Ambiente/SFB (2018). Relatório de Gestão de Florestas Públicas 2017. Brasília. Recuperado de http://www.florestal.gov.br/documentos/publicacoes/3531-relatorio-de-gestao-de-florestaspublicas-2017/file

Ministério de Meio Ambiente/IBAMA (2011). Monitoramento do desmatamento nos biomas brasileiros por satélite. Acordo de Cooperação Técnica MMA/IBAMA. Monitoramento do Bioma Cerrado 2009-2010. Brasília. Recuperado de http://www.mma.gov.br/estruturas/sbf_chm_rbbio/_arquivos/relatoriofinal_ cerrado_2010_final_72_1.pdf.

Ministério de Meio Ambiente/ICMBIO (2016). Parque Nacional de Itatiaia tem 51\% de área regularizada. . Brasília. Recuperado de https://www.icmbio.gov.br/portal/ultimas-noticias/20-geral/7972-parquenacional-de-itatiaia-atinge-51-de-area-regularizada.

Ministério de Meio Ambiente/ICMBIO (2017). Relatório de consolidação da aplicação do SAMGe 2016. Brasília. Recuperado de http://www.icmbio.gov.br/portal/images/stories/DMAG/Relatorio_Completo_2016. pdf.

Ministério de Meio Ambiente/CNUC (2011). Cadastro Nacional de Unidades de Conservação. Unidades de Conservação por Bioma. Brasília. Recuperado de http://www.mma.gov.br/areas-protegidas/cadastronacional-de-ucs.

Ministério de Meio Ambiente/CNUC (2018a). Tabela consolidada das Unidades de Conservação. Brasília. Recuperado de http://www.mma.gov.br/images/arquivo/80229/CNUC_JUL18\%20-\%20B_Cat.pdf.

Ministério de Meio Ambiente/CNUC. (2018b). Unidades de Conservação por bioma. Recuperado de http:// www.mma.gov.br/images/arquivo/80229/CNUC_JUL18\%20-\%20C_Bio.pdf.

Mittermeier, R., Gil, P.R., Hoffmann, M., Pilgrim, J.B., Brooks, T., Mittermeier, C.G., ...\& Fonseca, G.A.B. (2004). Hotspots Revisited: Earth's Biologically Richest and Most Endangered Terrestrial Ecorregions. México City: CEMEX.

Mochiutti, N.F.B., \& Guimarães, G.B. (2018). Communication for conservation - a case study of the movement in favor of the Devonian Escarpment Environmental Protection Area (Paraná State, Southern Brazil). Terrae Didatica, 14(4): 455-46. Recuperado de http://www.ppegeo.igc.usp.br/index.php/TED/ article/view/13270/12863.

Myers, N. (1997). Florestas Tropicais e suas Espécies: sumindo, sumindo...? In O.E. Wilson (ed.). Biodiversidade. Rio de Janeiro: Nova Fronteira.

Myers, N., Mittermeier, C.G., Mittermeier, G.A.B.F., \& Kent, J. (2000). Biodiversity Hotspots for conservation priorities. Nature, 403:853-858. 
Oliveira, W.A. (2017). Turismo, Unidades de Conservação e inclusão social: uma análise da área de Proteção Ambiental dos Recifes de Corais (APARC) e Área de Proteção Ambiental de Jenipabu (APAJ). (Dissertação de Mestrado em Turismo). Universidade Federal do Rio Grande do Norte, UFRN, Natal, RN, Brasil.

Prates, A.P., \& Souza, N.O.M. (2014). Panorama Geral das Áreas Protegidas no Brasil: Desafios para o cumprimento da Meta 11 de AICHI. In N. Bensusan, \& A.P. Prates (Orgs.) A diversidade cabe na Unidade? Áreas Protegidas no Brasil. (pp. 82-119). Brasília: IEB.

Quintas, J. S. (2009). Educação Ambiental de gestão ambiental pública: a construção do ato pedagógico. In C. F. B. Loureiro, P.P. Layrargues, \& R.S.C. Castro (Orgs.). Repensar a Educação Ambiental: um olhar crítico. São Paulo: Cortez.

Quintas, J.S. (2006) Por uma educação ambiental emancipatória: considerações sobre a formação do educador para atuar no processo de gestão ambiental. In J.S. Quintas (Org.). Pensando e praticando a educação ambiental na gestão do meio ambiente. (3a.ed., pp. 13-22). Brasília: IBAMA/MMA.

Romariz, D.A. (2008). Biogeografia: conceitos e temas. São Paulo: Scortecci.

Salles, P.S.B.A. (2008). Paradigmas e paradoxos: solo, água e biodiversidade no Distrito Federal. In N. Bensusan (Org.). Seria melhor mandar ladrilhar? Biodiversidade; como, para que e por quê. (2a ed., pp. 259-275). Brasília: Ed. UnB.

Santa Cruz Cabrália (2016). Plano Municipal de Conservação e Recuperação da Mata Atlântica de Santa Cruz Cabrália.

Santos, S.A. (2018). As Unidades de Conservação no Cerrado frente ao processo de conversão. (Dissertação de Mestrado em Geografia). Universidade Federal de Goiás, UFGO, Goiânia, GO, Brasil.

Saquet, M.A. (2007). Abordagens e concepções de território. São Paulo: Expressão ao Popular.

Saquet. M.A. (2009). Por uma abordagem territorial. In M.A. Saquet, \& E.S. Sposito (Orgs.) Territórios e territorialidades: teorias, processos e conflitos. (pp. 73-94). São Paulo: Expressão Popular.

Silva, C.E.M. (2005). Lugar-habitat e Lugar-mercadoria: Territorialidades em tensão no domínio do Cerrado. In A. Zhouri, K. Laschefski, \& D.B. Pereira (Orgs.). A insustentável leveza da política ambiental: desenvolvimento e conflitos socioambientais. (pp. 217-244). Belo Horizonte: Autêntica.

Silva, M.S.F. (2012). Territórios da Conservação: uma análise do potencial fitogeográfico das UCs de uso sustentável em Sergipe. (Tese de Doutorado em Geografia). Universidade Federal de Sergipe, UFSE, São Cristóvão, SE, Brasil.

Silva, M.S.F.; \& Souza, R.M. (2009). Unidades de Conservação como estratégia de gestão territorial dos recursos naturais. Terr@Plural, 3(2):241-259.

Silva, M.S.F., \& Souza, R.M. (2013). Territórios protegidos e arenas de conflito nas Unidades de Conservação de Uso Sustentável em Sergipe, Brasil. Scripta Nova, 17(445). Recuperado de http:/ / www.ub.edu/geocrit/ sn/sn-445.htm

Sorrentino, M., Trajber, R., Mendonça, P., \& Ferraro Junior, L.A. (2005). Educação ambiental como política pública. Educação e Pesquisa, 31(2): 285-299.

SOS Mata Atlântica/ Instituto Nacional de Pesquisas Espaciais (2018). Atlas dos remanescentes florestais da Mata Atlântica período 2016-2017:relatório técnico. São Paulo.

Souza, M.J.L. (2003). O território: sobre espaço e poder, autonomia e desenvolvimento. In Castro, I.E., Gomes, P.C.C. \& Corrêa, R.L. (Orgs.). Geografia: Conceitos e Temas. (pp. 77-116). Rio de Janeiro: Bertrand Brasil.

Zanirato, S.H. (2010). O patrimônio natural do Brasil. Projeto História, 40:127-145. Recuperado de https:// revistas.pucsp.br/index.php/revph/article/view/6127/4449

Data de submissão: 24/abr./2019

Data de aceite: $10 /$ jan./2020 